\title{
Evaluation of Cytomegalovirus (CMV) in Abortion Compared with Embryos Vaginal Delivery by Using PCR
}

\section{ART ICLE INF O}

\section{Article Type}

Original research

\section{Authors}

Zaker Bostanabad S.*PhD,

Rahimi M.K. ${ }^{1} P h D$,

Mahdavi M. ${ }^{2} M S c$,

Pourazar Sh. ${ }^{3} \mathrm{MSc}$

\section{A B S T RA C T}

Aims Cytomegalovirus is a major cause of congenital abnormalities, mental retardation, abortion and neonatal infections. The aim of this study was to determine the prevalence of CMV in amniotic fluid by PCR method and to compare it between the patients with abortion and women with normal delivery.

Materials \& Methods This case-control and descriptive-analytic study was conducted on 120 women referred to Amiralmomenin, Javaheri and Bouali hospitals in 2010. The women were studied in two case $(n=60)$ and a control $(n=60)$ groups including the mothers with abortions and mothers with normal delivery, respectively. The information of the participants was collected using a questionnaire and a PCR method was used for microbiological examination for CMV. Data were analyzed by SPSS 13 using chi-square test.

Findings Totally, the PCR results were positive in 16 (13.3\%) patients. In the case group, $26.7 \%$ of the women had a history of CMV. The PCR results were negative for the control group. Totally, the prevalence of CMV was $13.3 \%$. In the case group, $61.7 \%$ of patients had no abortion history, $30.0 \%$ had one abortion and $8.3 \%$ had two abortions, previously. In the case group, abortions occurred before 20 weeks of gestation in $21.7 \%$ of women and $78.3 \%$ of abortions occurred after 21 weeks of pregnancy. There was a significant relationship between the incidence of CMV and the number of abortions in the mothers and abortion time.

Conclusion Due to the importance of rapid and correct diagnosis of pathogens before emergence of its complications, the molecular method can be useful for the purpose and even for the low level of pathogenicity.

Keywords CMV; Abortion; PCR

\section{I T A T I O N L I N KS}

[1] Microbiology relevant to recurrent miscarriage [2] Genital listeriosis as a cause of repeated abortion [3] Immunity to cytomegaloviruses in women with unexplained recurrent spontanous abortion [4] Evaluation of Parvo B19, CMV and HPV viruses in human aborted materialusing the polymerase chain reaction technique [5] Persistence of IgM antibodies to CMV-induced late antigen in pregnancy andpostpartum [6] ELISA antibodies to cytomegalovirusin pregnant patients prevalencein andcorrelation with spontaneous abortion [7] The diagnostic value of anti-CMV HPV-B19 antiviral antibodiesin studies on causes of recurrent aboirtions [8] Diagnostic and prognostic value of specific immune response to Cytomegaloviruses inpregnant women with a history of habitual abortion [9] Congenital cytomegalovirus infection in pregnancy: A case report of fetal death in a CMV-infected woman [10] Evaluation of immunity against CMV in Azarbaijan female population [11] Fatal congenital cytomegalovirus infection following recurrent aternal infection after a 7-year interval [12] Secondary cytomegalovirus infection can cause severe fetal sequelae despit maternal preconceptional immunity [13] CMV seroconversion in pregnants and the incidence of congenital CMV infection [14] Seroprevalence of Cytomegalovirus (CMV) in Kashmir valley-a preliminary study [15] Medical Microbiology [16] Late CMV disease and/or pecursence in renal transplant recipients with pronged oral garciclovirprophylanis [17] Cytomegalovirus infection after organ transplantation: An update ith special emphasis on renal transplantation [18] Cytomegalovirus antigenemia [19] Cytomegalovirus antigen detection in peripheral blood leukocytes after allogeneic narrowtransplantation [20] Comparisonbetweenviremiaandntigenemiafordetectionofcytomegalovirus in blood [21] The lower matrix protein pp65 is the principal viral antigen present in peripheral blood leukocytes during an active cytomegalovirus infection [22] Quantification of human cytomegalovirus viremia by using monoclonal antibodies to different viral proteins [23] Cytomegalovirus infection in the pregnantmother, fetus, and newborn infant [24] Perinatal cytomegalovirus and toxoplasmosis: Challenges of antepartum therapy [25] Cytomegalovirus infection of the cervix detected by cytology and histology: A report of five cases [26] Disseminated cytomegalovirus infection of the female genital tract

\section{Article History}

Received: February 20, 2014

Accepted: May 19, 2016

ePublished: June 15, 2017 
علايم عفونت سيتومكالوويروس مادرزادى را هنگام تولد از خود

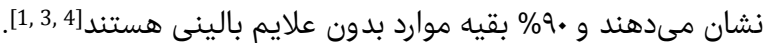

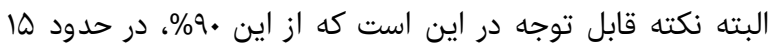

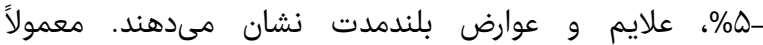

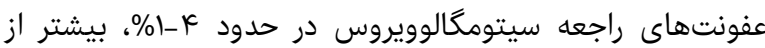

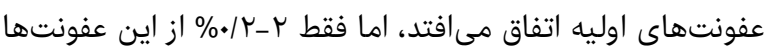

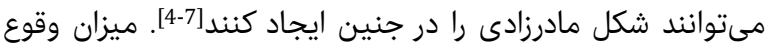

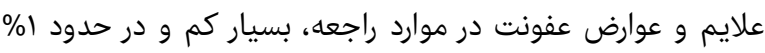

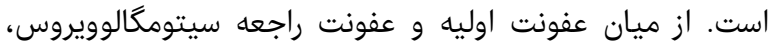

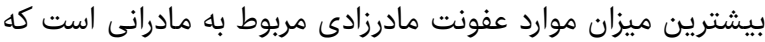

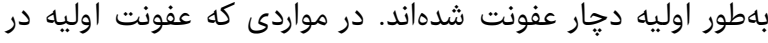

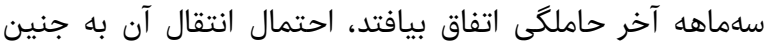

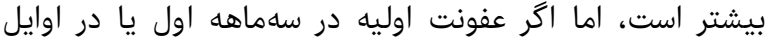

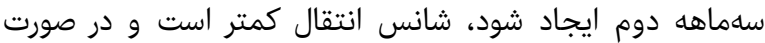

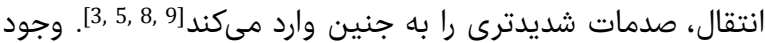

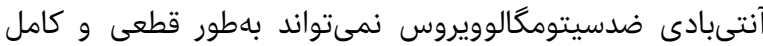

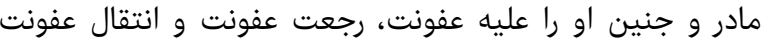

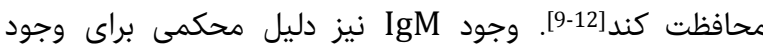

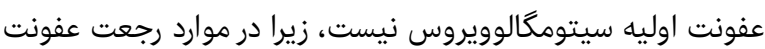

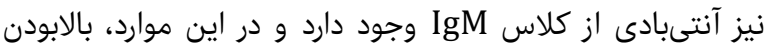

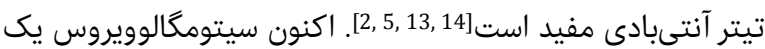

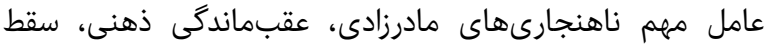

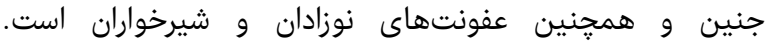

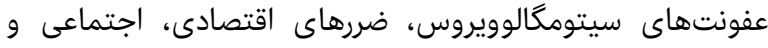

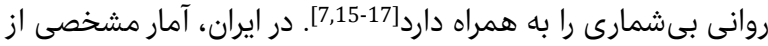

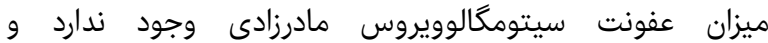

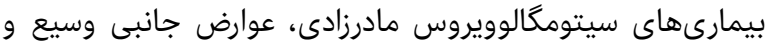

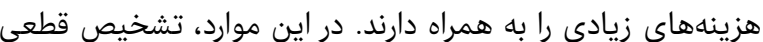

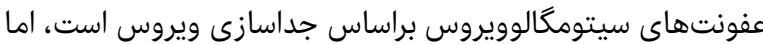

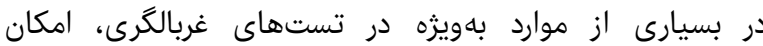

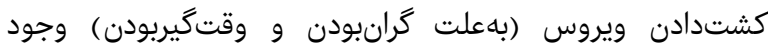

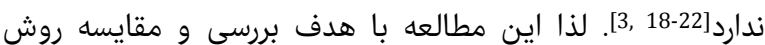

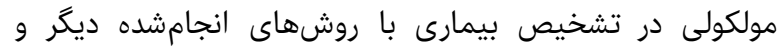
اهميت روش مولكولى بلمنظور تست سريع و صحيح انجام شد. رئ.

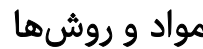

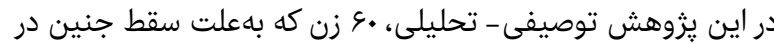

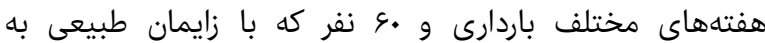

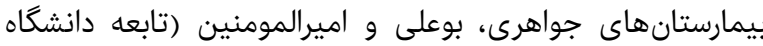

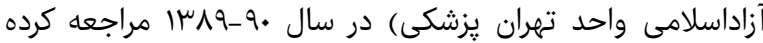

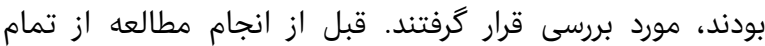

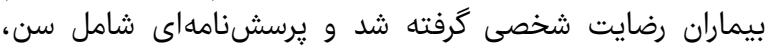

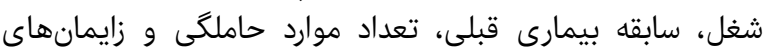

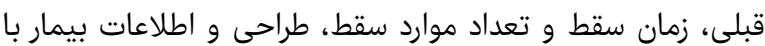
مصاحبه در آن وارد شد.

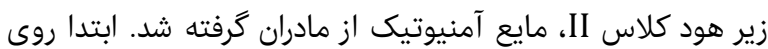

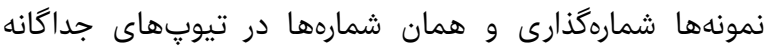

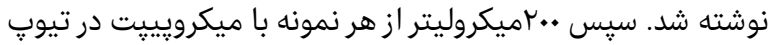

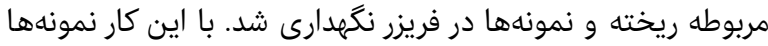

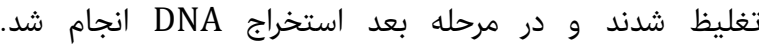

بررسى ميزان فراوانى سيتو مكالو ويروس (CMV)

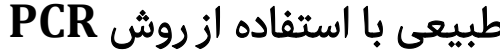

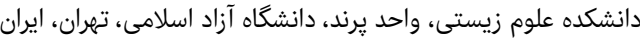

PhD محمدكريم رحيمى علئين

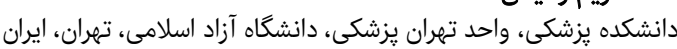

زينب مهدوى دSc

بخش مولكولى بيمارستان خاتم، تهران، ايران

MSc شاهين يورآذر موليمارست

"بخش مولكولى آزمايشكاه مسعود" و "بيمارستان فوق تخصصى صارم"، تهران، ايران

جكيده اهداف: سيتومكالوويروس يك عامل مهم ناهنجارىهاى مادرزادى، عقبماندكى إنى

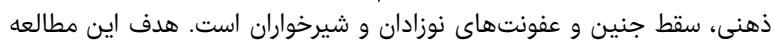

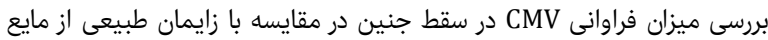

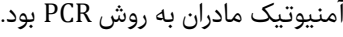

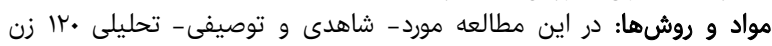

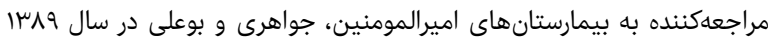

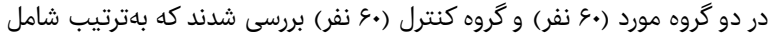

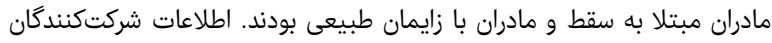

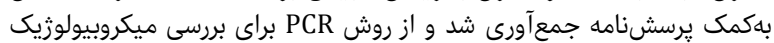

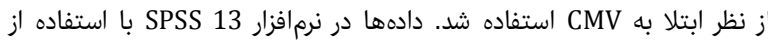

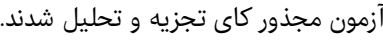

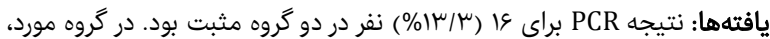

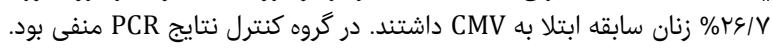

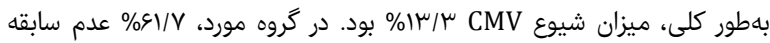

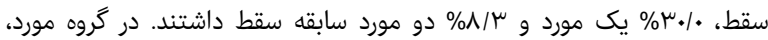

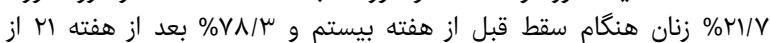

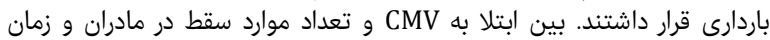
سقط رابطه معنى دارى وجود داشت. بارئ.

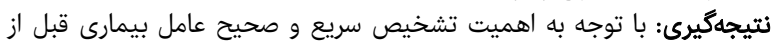

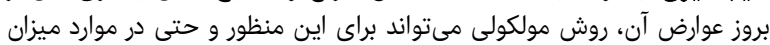

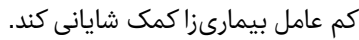
كليدوازمها: سيتومكالوويروس، سقط جنين، PCR

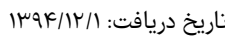

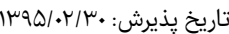
كويسنده مسئول: saeedzaker20@yahoo.com

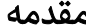

سيتومكالوويروس (CMV) يكى از اعضاى خانواده هريسويريديده،

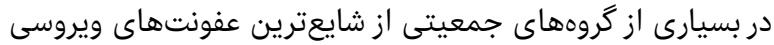

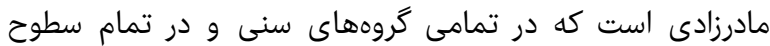

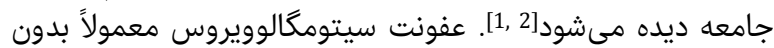

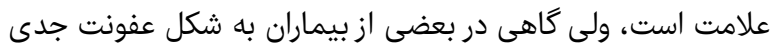

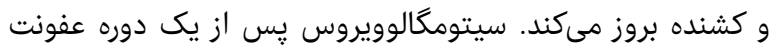

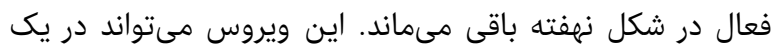

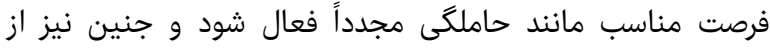

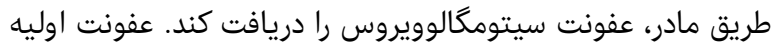

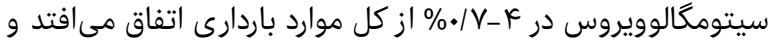

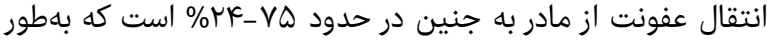

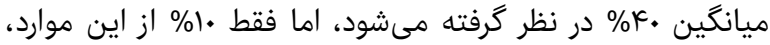


عفونت سيتومكالوويروس معمولاً بدون علامت است، ولى گاهى در

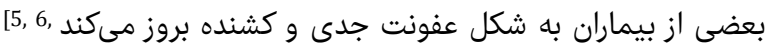

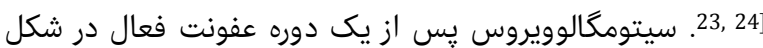

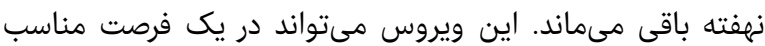

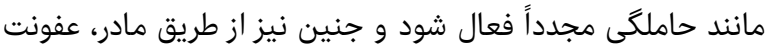

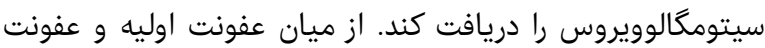

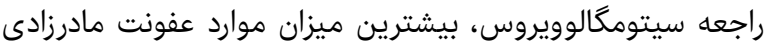

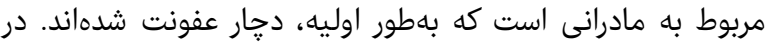

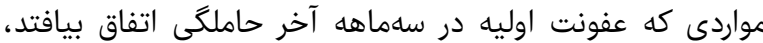

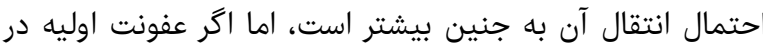

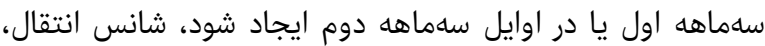

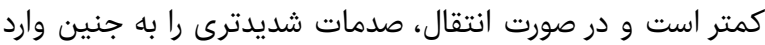

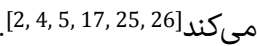

بنابراين براى تشخيص باموقع اين عامل در موارد مختلف و شرايط

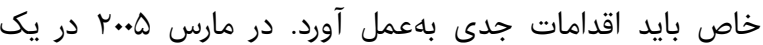

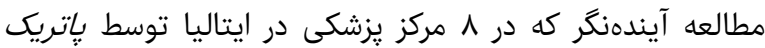

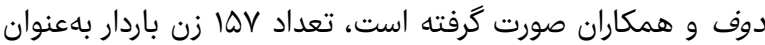

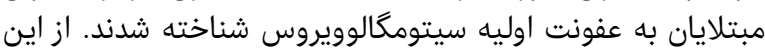

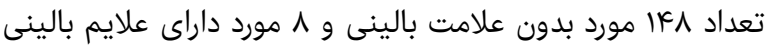

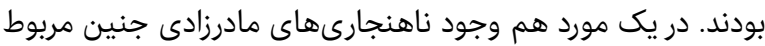

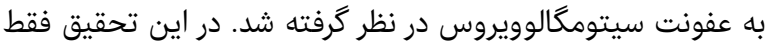

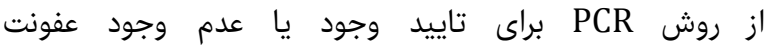

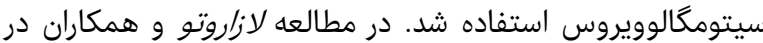

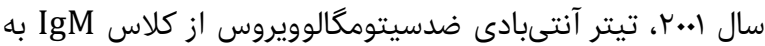

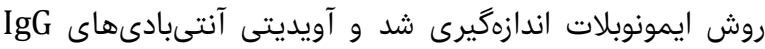

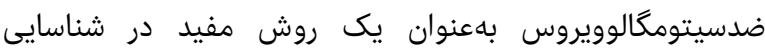

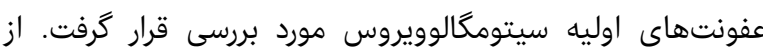

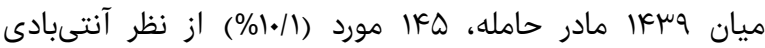

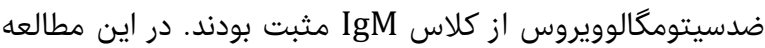

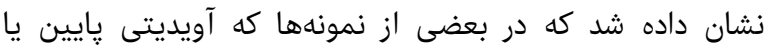

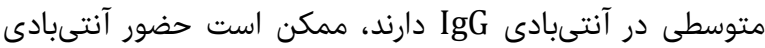

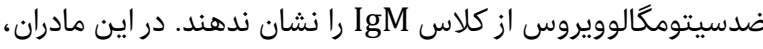

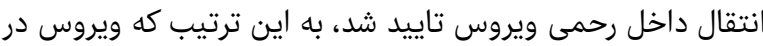

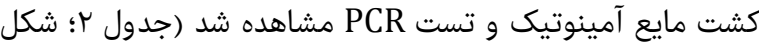

.$(1$

جدول Y) بررسى رابطه بين زمان سقط با نتايج PCR منيى PCR

\begin{tabular}{|c|c|c|c|}
\hline مجموع & PCR مثبت PCR & منفى PCR & Time abortion \\
\hline & & & كمتر از •rهفته \\
\hline $1 \pi$ & 1. & $\mu$ & ت تعداد \\
\hline $1 . .1$. & $V \varepsilon / 9$ & $r \mu / l$ & $\%$ within Time Abortion \\
\hline $\mathrm{rI/V}$ & ST/Q & s/A & $\%$ within PCR Finding \\
\hline rI/V & $18 / V$ & $\Delta / \cdot$ & درصد ازكل \\
\hline & & & بيشتر از اYهفته \\
\hline $\mathrm{kV}$ & 4 & kI & 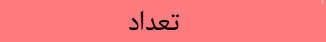 \\
\hline $1 . .1$ & $\mid r / \Lambda$ & $\wedge \mathrm{V} / \mathrm{r}$ & $\%$ within Time Abortion \\
\hline$\vee \Lambda / \mu$ & $\mu \vee / Q$ & $q \mu / r$ & \% within PCR Finding \\
\hline$\vee \wedge / \mu$ & $1 \%$ & 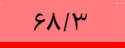 & درصد از كل \\
\hline c. & 18 & $k F$ & مجموع \\
\hline $1 . .1$. & rE/V & $V \mu / \mu$ & $\%$ within Time Abortion \\
\hline $1 . .1$. & $1 . .1$. & $1 . .1$ & \% within PCR Finding \\
\hline $1 . .1$. & re/V & $v \mu / \mu$ & درصد از كل \\
\hline
\end{tabular}

شناسايى مولكولى به روش واكنش زنجيرهاى يليمراز (PCR)

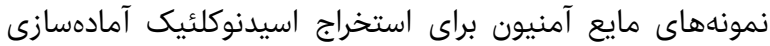

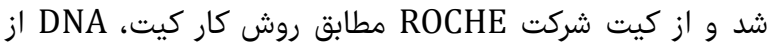

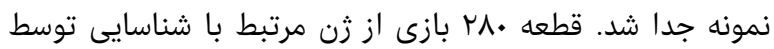

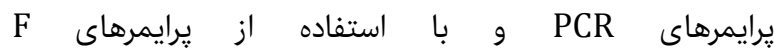
R و GTAGCTGGCATTGCGATTGGT TCCAACACCCACAGTACCCGT

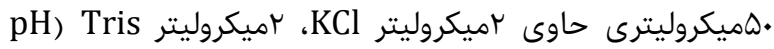

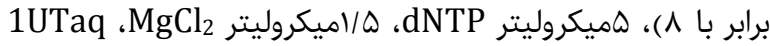

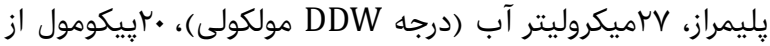

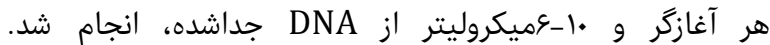

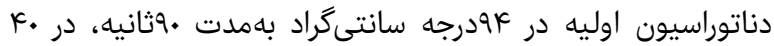

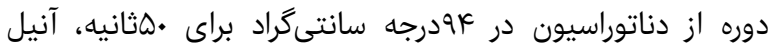

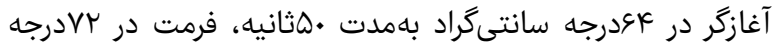

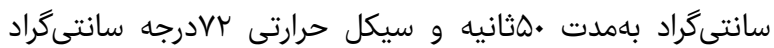

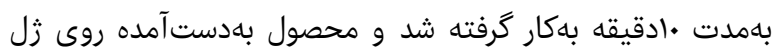

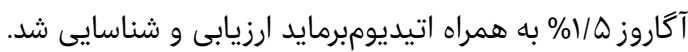

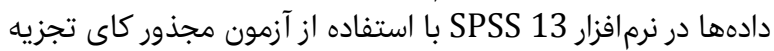

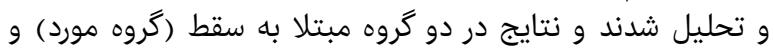
گروه با زايمان طبيعى مقايسه شدند.

\section{يافتهها}

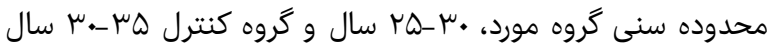

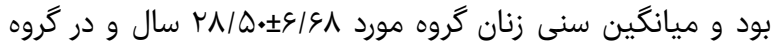

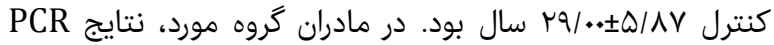

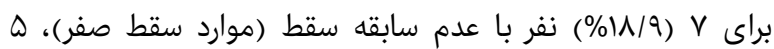
نفر با يكبار سابقه سقط و FV/N)

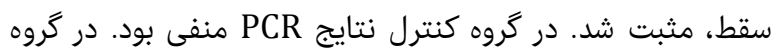

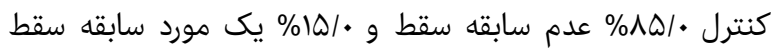

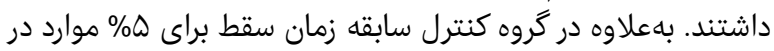

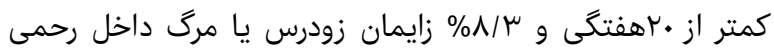

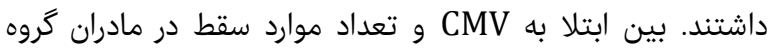

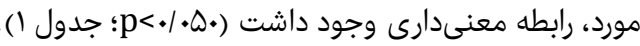

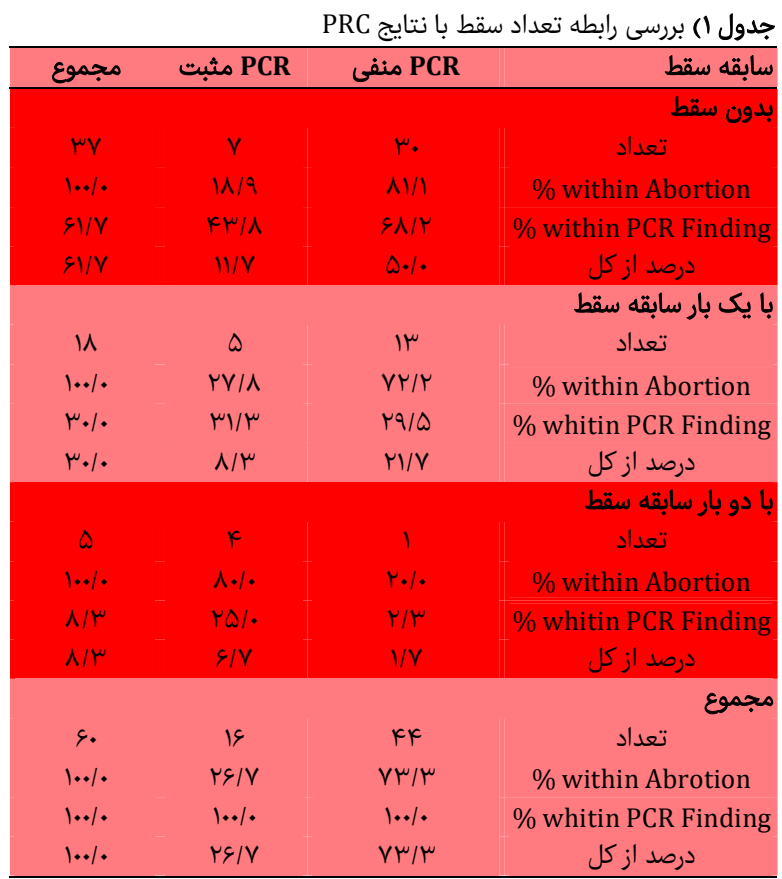

Volume 2, Issue 1, Spring 2017 


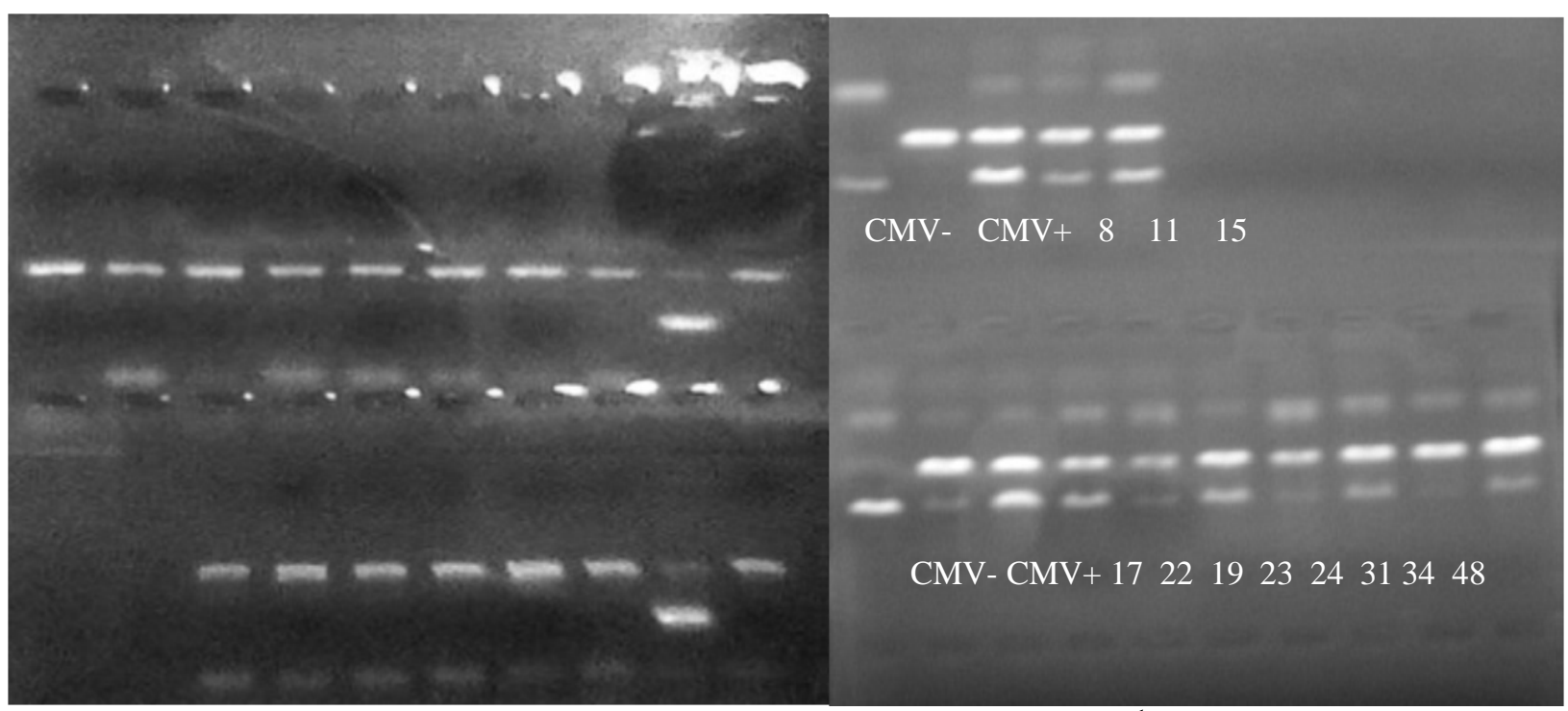

شكل () نمونههاى PCR داراى CMV منفى در گروه شاهد (مادران با زايمان طبيعى)

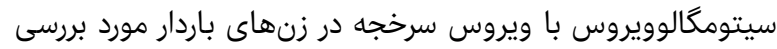

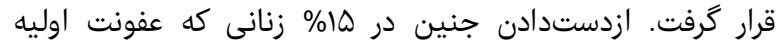

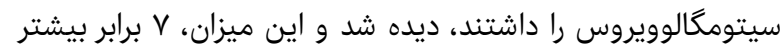

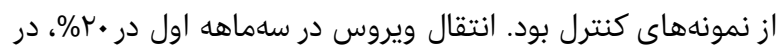

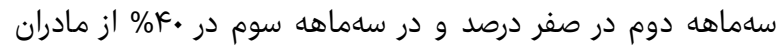

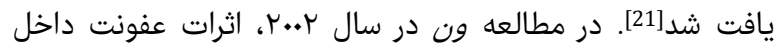

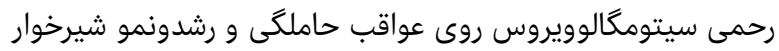

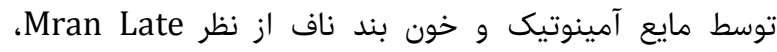
ويروس سيتومگال به روش گروهى كه در فرزندان يا خون بند ناف، آنتىبادى از كلاس

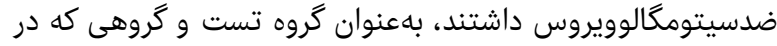

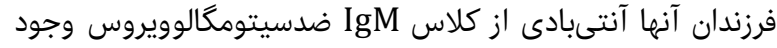

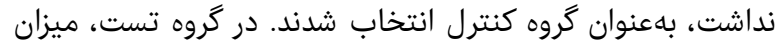

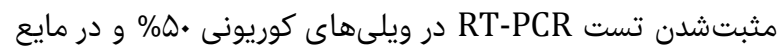

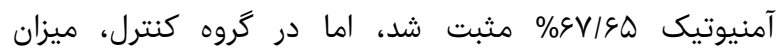

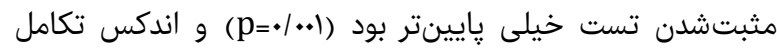

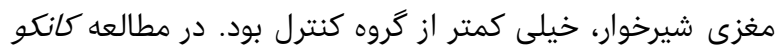

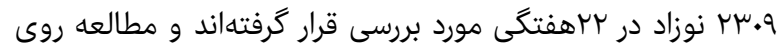

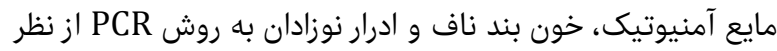

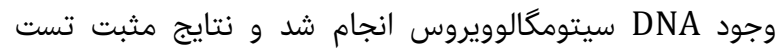

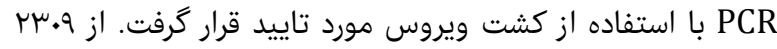

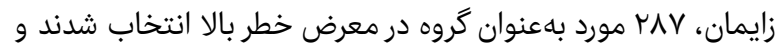

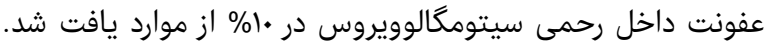

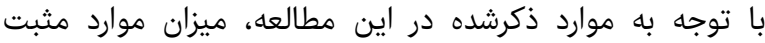

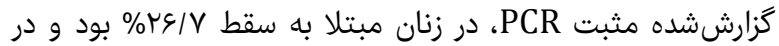

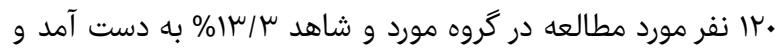

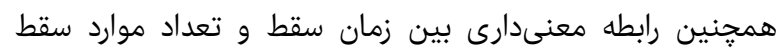

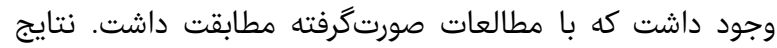

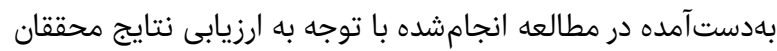

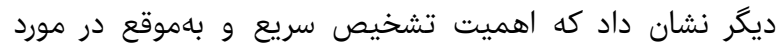

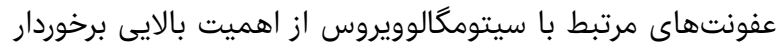

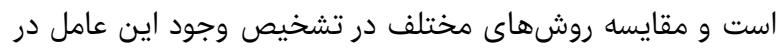

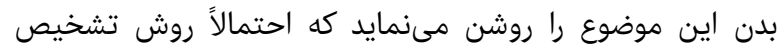

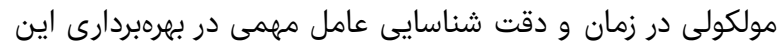

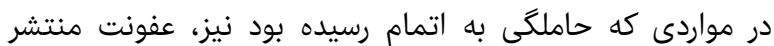

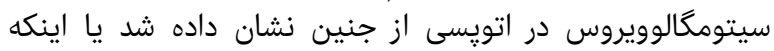

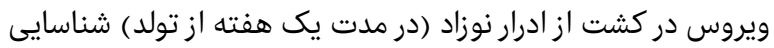

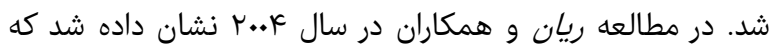

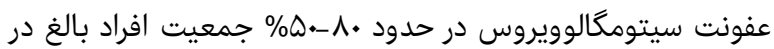

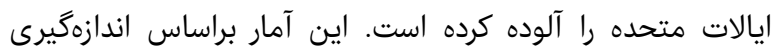

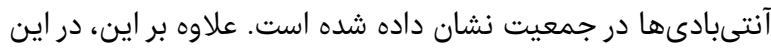

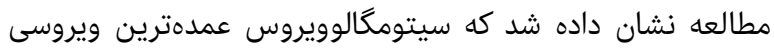

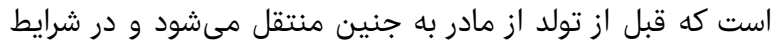

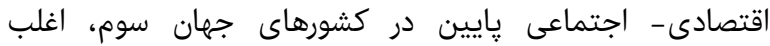

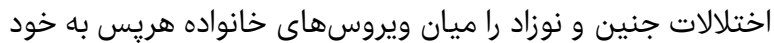

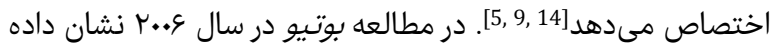

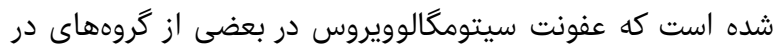

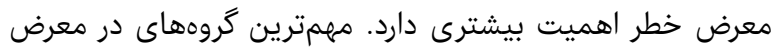

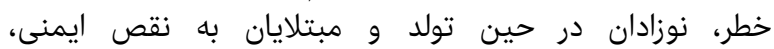

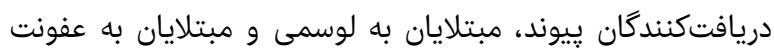

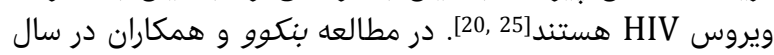

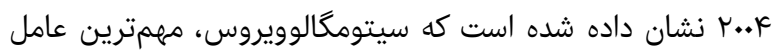

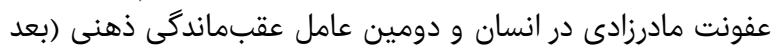

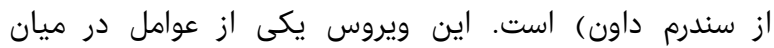

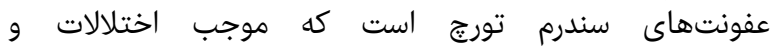
ناهنجارىهاى مادرزادى مىشود. درى ايالات متحده، شيوع عفورنت

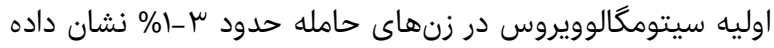

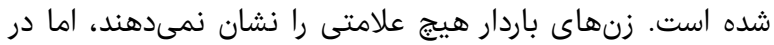

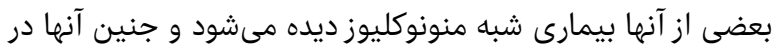

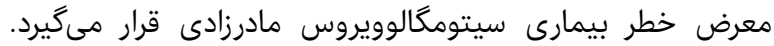

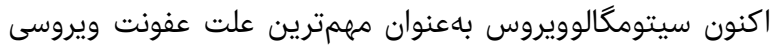

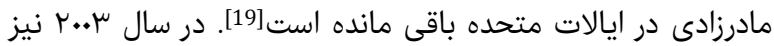

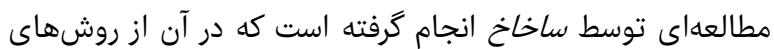

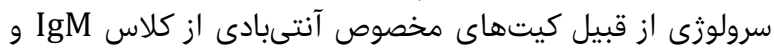

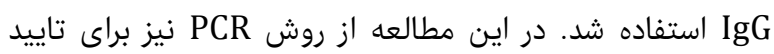

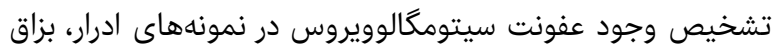

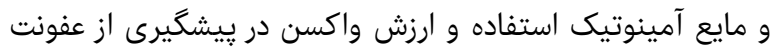

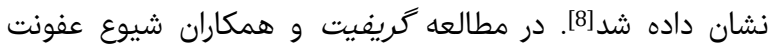


بر برسى ميزان فراوانى سيتو مكالو ويروس (CMV د.... در سقط جنين در مقايسه با زايمان the polymerase chain reaction technique. Eur J Obstet Gynecol Reprod Biol. 1998;76(2):169-73.

5- Gartner L, Kunkel M, Oberender H. Persistence of IgM antibodies to CMV-induced late antigen in pregnancy andpostpartum. Acta Virol. 1983;27(1):86-8.

6- Luerti M, Santini A, Bernini O, Castiglioni M, Ragni MC. ELISA antibodies to cytomegalovirus in pregnant patients prevalence in andcorrelation with spontaneous abortion. Biol Res Pregnancy Prinatal. 1983;4(4):181-3.

7- Szkaradkiewicz A, Pieta P, Tułecka T, Breborowicz G, Słomko Z, Strzyzowski P. The diagnostic value of antiCMV HPV-B19 antiviral antibodiesin studies on causes of recurrent aboirtions. Ginekol Pol. 1997;68(4):181-6. [Polish]

8- Sukhikh GT, Dadal'ian LG, Van'ko LV, Kalafati TI, Sidel'nikova VM. Diagnostic and prognostic value of specific immune response to Cytomegaloviruses inpregnant women with a history of habitual abortion. Akush Ginekol (Mosk). 1992;(3-7):30-3. [Russian]

9- Kost BP, Mylonas I, Kästner R, Rack B, Gingelmaier A, Friese K. Congenital cytomegalovirus infection in pregnancy: A case report of fetal death in a CMV-infected woman. Arch Gynecol Obstet. 2007;276(3): 265-8.

10- Rajaii, M, Pourhassan A. Evaluation of immunity against CMV in Azarbaijan female population. Iran J Clin Infect Dis. 2008;3(3):143-8.

11- Ergun UG, Bakaris S, Ucmak H, Ozbek A. Fatal congenital cytomegalovirus infection following recurrent aternal infection after a 7-year interval. Saudi Med J. 2007;28(2):264-7.

12- Zalel Y, Gilboa Y, Berkenshtat M, Yoeli R, Auslander R, Achiron R, et al. Secondary cytomegalovirus infection can cause severe fetal sequelae despit maternal preconceptional immunity. Ultrasound Obstet Gynecol. 2008;31(4):417-20.

13- Satilmiş A, Güra A, Ongun H, Mendilcioğlu I, Colak D, Oygür N. CMV seroconversion in pregnants and the incidence of congenital CMV infection. Turk J Pediatr. 2007;49(1):30-6.

14- Ione R, Fomda BA, Thokar M, Wani T, Kakru D, Shaheen R, et al. Seroprevalence of Cytomegalovirus (CMV) in Kashmir valley-a preliminary study. JKPractitioner. 2004;11(4):261-2.

15- Goering R, Dockrell, Zuckerman M, Roitt I, chiodini P. Medical Microbiology. 3rd Edition. Edinburgh: Mosby; 2004.

16- Gomez E, Loures A, Smelon J, Baltar. Late CMV disease and/or pecursence in renal transplant recipients with pronged oral garciclovirprophylanis. Transplantation smedzin, 2003.

17- Vanson WJ, The TH. Cytomegalovirus infection after organ transplantation: An update ith special emphasis on renal transplantation. Transpl Int. 1989;2(3):147-64.

18- The TH, Van Der Bij W, Van Den Berg Ap, Van Der Gissen M, Sprenger Hg, Van son WJ. Cytomegalovirus antigenemia. Rev inf Dis. 1990;12:737-44.

19- Boeckh M, Bowden RA, Goodrich JM, Pettinger M, Meyerst J. Cytomegalovirus antigen detection in peripheral blood leukocytes after allogeneic narrow transplantation. Blood. 1992;80:1358-64.

20- Van Der Bij W, Schirm J, Torensma R, Van Son WJ, Tegzess AM, The TH. Comparison between viremia and ntigenemia for detection of cytomegalovirus in blood. J Clin Microbiol. 1988;26(12):2531-5.

21- Grefte JM, Van Der Gun BT, Sehmolke S, Van Der Giessen M, Van Son WJ, Plachter B, et al. The lower matrix protein pp65 is the principal viral antigen present

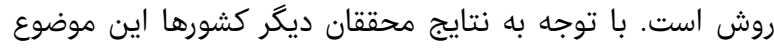

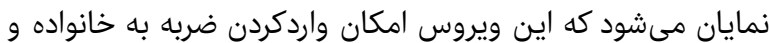

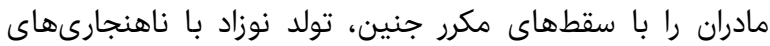

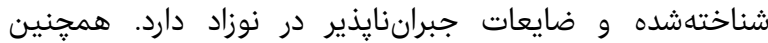

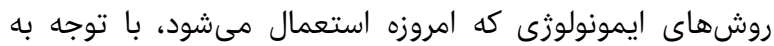

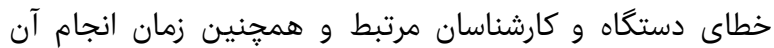

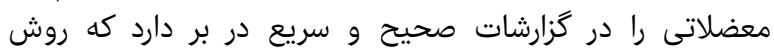

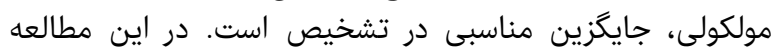

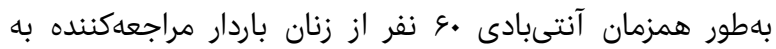

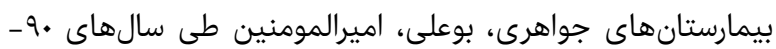

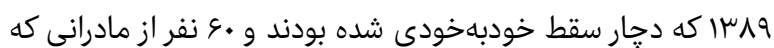

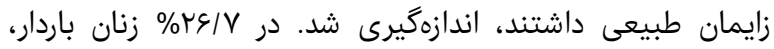

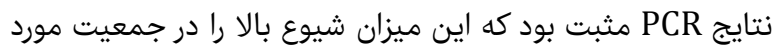

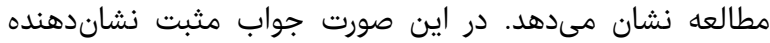

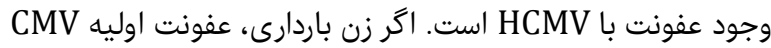

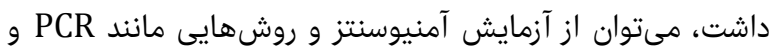

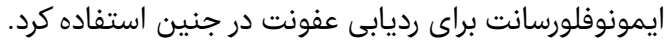

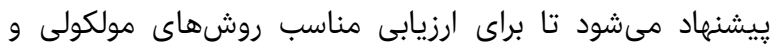

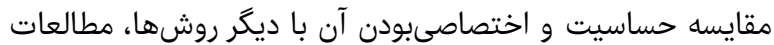

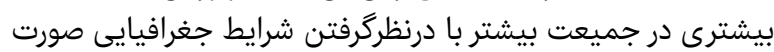
يذيرد. - ميثن. نتيجه نيرى با توجه به اهميت تشخيص سريع و صحيح عامل بيمارى قبل از

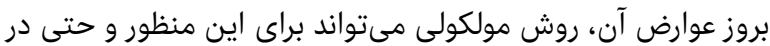
موارد ميزان كم عامل بيمارى زا كمك شايانى كند.

تشكر و قدردانى: موردى از سوى نويسندكان ذكر نشده است.

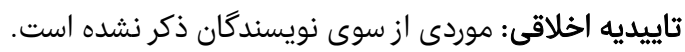

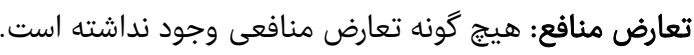

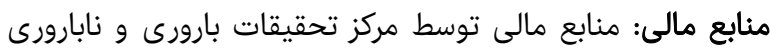

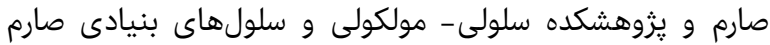
تامين شده است. سهم نويسندگان: سعيد ذاكر بست إنتان آباد (نويسنده اول)، نكارنده

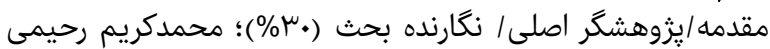

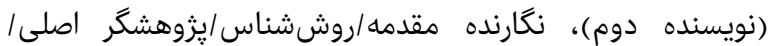

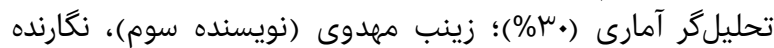

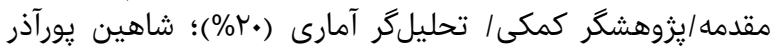

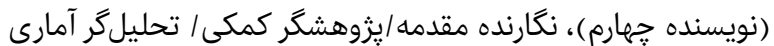

$$
\text { منابع }
$$

1- Summers PR. Microbiology relevant to recurrent miscarriage. Clin Obstet Gynecol. 1994;37(3):722-9.

2- Rappaport F, Rabinovitz M, Toaff R, Krochik N. Genital listeriosis as a cause of repeated abortion. Lancet. 1960;1(7137):1273-5.

3- Rad cliffe JJ, Hart CA, Francis WJ, Johnson PM. Immunity to cytomegaloviruses in women with unexplained recurrent spontanous abortion. Am J Reprod Immunol Microbiol. 1986;12(4):103-5.

4- Sifakis S, Ergazaki M, Sourvinos G, Koffa M, Koumantakis E, Spandidos DA. Evaluation of Parvo B19, CMV and HPV viruses in human aborted materialusing 
24- Piper JM, Wen TS. Perinatal cytomegalovirus and toxoplasmosis: Challenges of antepartum therapy. Clin Obstet Gynecol. 1999;42(1):81-96.

25- Huang JC, Naylor B. Cytomegalovirus infection of the cervix detected by cytology and histology: A report of five cases. Cytopathology. 1993;4(4):237-41.

26- Friedmann W, Schäfer A, Kretschmer R, Lobeck H. Disseminated cytomegalovirus infection of the female genital tract. Gynecol Obstet Invest. 1991;31(1):56-7.

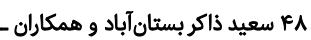
in peripheral blood leukocytes during an active cytomegalovirus infection. J Gen Virol. 1992;73:2923-32. 22- Gema G, Revello MG, Percivalle E, Zavattoni M, Parea M, Battaglia M. Quantification of human cytomegalovirus viremia by using monoclonal antibodies to different viral proteins. J Clin Microbiol. 1990;28(12):2681-8.

23- Nelson CT, Demmler GJ. Cytomegalovirus infection in the pregnant mother, fetus, and newborn infant. Clin Perinatol. 1997;24(1):151-60. 